\title{
Self-driving Car Project in Embedded Systems Class
}

\section{Maddumage Karunaratne, University of Pittsburgh, Johnstown}

Dr. Maddumage Karunaratne is an Associate Professor and the Head of the Electrical Engineering Technology department at the University of Pittsburgh at Johnstown, PA. The department offers two undergraduate degrees in Electrical Engineering Technology and Computer Engineering Technology. Dr. Karunaratne earned a Bachelor of Science degree from the University of Moratuwa (Sri Lanka), a Master of Science from the University of Mississippi (Oxford), and a Ph.D. from the University of Arizona (Tucson).

Before joining academia, he gained fourteen years of extensive industry experience working in the semiconductor industry performing software development, application engineering, design, testing and verification of digital integrated circuits. He has taught electrical and general engineering technology classes at Pitt-Johnstown since 2004.

His research and teaching interests include Semiconductor circuit Testing and Verification, Low Power Design Analysis, Digital and Embedded Systems, Electromagnetic Wave Scattering, and IC Design Automation Software development. He has authored or coauthored 27 publications and he holds two US patents.

He can be reached at maddu@pitt.edu 209 Engineering and Science Building University of Pittsburgh at Johnstown Johnstown, PA 15904 


\title{
A Self-Driving Car project in Embedded Systems Class
}

\begin{abstract}
:
With every increasing integrated circuit manufacturing prowess, today an astounding array of devices include embedded microcontrollers to provide connectivity, automation, power efficiency along with entertainment to end user. One example is the widely used light bulbs. They first became LEDs and then miniature controllers were added that can be programmed using a cell phone remotely. The widely known term smart device really comes from embedded microcontrollers in majority of the devices. Silicon manufactures have launched hobby industries around inexpensive electronics, particularly microprocessor boards, with more capabilities and easy to program systems such as Raspberry Pi and Arduino. For individual developer or capable consumer those devices offer vast levels of customization.
\end{abstract}

When electrical and computer engineers are trained, it is imperative that nearly all acquire some level of exposure to embedded microcontroller and associated software development skills to effectively function as engineers in their careers. The nature of work performed in industry changes as they progress in careers. Lack of such exposure and experience will constrain their opportunities in different technical fields and even managerial advancements.

At this university, electrical engineering and computer engineering majors take one semester course in microcontrollers to learn embedded system developments in their junior year preceded by a $\mathrm{C}$ programming course and an electronics course. This course facilitates their understanding of digital controllers and most of the senior capstone projects would select one or two microcontrollers as the heart of the project. Students have used Raspberry Pi, Arduino, and Freescale Dragon boards which the course and labs are based on due to its simplicity and legacy. With vast processing capabilities of electronics, Google and others are trying to push automation to a new degree with self-driving vehicles which have to read and interpret moving and stationary objects, black and white surface lines, light colors, etc. To provide more hands on experience and a flavor of such real world emerging technologies, the author recently introduced an automated vehicle project to students in lieu of the final written comprehensive assessment for the Embedded Systems course.

This paper discusses the content and experience in having an automated line tracking and moving object avoidance project as final class assessment in Embedded Systems class. The project is to be done by two student groups with limited skeleton code and help from the instructor within a few weeks' time toward end of the course. Students mount Dragon 12 microcontroller boards on cars after removing remote controller units, but leaving the motors intact. Some use 4-wheel drive cars and separate driver circuits along with sonar sensors, sound sensors and line sensors. Students learn to be creative and sharpen their engineering skills. Instructor evaluates the devices on a track shown to them on paper, but not made available for trials. The track contains left-right curves, cross roads, and moving objects are used to test their vehicles in front of an audience. 
part I: introduction

Since the transistor was invented many decades ago, semiconductor and electronics industry continues to make vast strides in providing functionally rich inexpensive electronic devices for consumers and industries. In recent years that trend has even accelerated due to low power consumption of electronic processors and sensors allowing devices to be portable. Smart robots - both personal and industrial are proliferating fueled by efficient manufacturing combined with energy dense battery technology. At these devices contain embedded controllers and computing processors termed as microcontrollers which typically offer less performance than the latest processors used in laptop and desktop personal computers.

Electrical and computer engineers will not be successful without having a good skill set and an understanding of how these proliferating smart devices work in terms of processing data and providing various control functions for the device such as voice and image recognition, speaking, precision movements, etc. While most of electrical and computer baccalaureate graduates may not enter careers to design semiconductor devices, they might still be designing or maintain systems developed using manufactured embedded processors. Also would still need to understand the trends, adapt, and adopt the technologies to be successful in their careers.

Teaching Embedded Systems has been around for a long time for the purpose of giving the skills to students to develop such control and communication systems in both software and hardware. As has been the case in the beginning, electronic embedded systems eventually are constrained by power, memory, processing capacity and ultimately the overall efficiency. The programming language and the platform of choice is mostly $\mathrm{C}$ or $\mathrm{C}++$ due to its efficiency in memory allocation, run time and ability to directly manipulate data in hardware components, although higher level functional languages such as Python are becoming popular.

Both computer and electrical engineering programs meet the stated program educational objective of "Adapt to technological change," and the student outcome of "having an appropriate mastery of the knowledge, techniques, skills and modern tools of their disciplines." Every student in both programs takes an Embedded Systems course along with a lab course in their junior year of studies. By that time, students have taken a Digital Electronics course along with labs which would help them understand hardware in Embedded systems. Their prior semester long programming in $\mathrm{C}$ language helps them write C-programs to effectively utilize the microcontroller for this course. This course has three lecture periods and an associated 3-hour lab per week. Among assignments and assessments, the course includes two exams and a final exam given in the form of a project limited to 2 students per group to use the actual hardware board. Due to simplicity and versatility, this course is taught around Freescale HCS12 microcontroller, and the labs are done using Dragon12Plus boards with additional sensors and components. In addition, the course teaches how the embedded controller communicates with the external devices using different data communication protocols.

This paper discusses the Embedded Systems course in general, and the automated car project used as the final examination in detail. After many quiz assessments and written exams, students put their learning into practice by building and programming a toy car to travel automatically along a marked path with moving obstacles and tight turns. It has to rely on tracking a contrasting (black on white) line to keep it on the path and make turns or other movements. Additional sensors are used to detect 
obstacles. Students' feedback has always been positive, and their comments indicate that they learned much more by doing the project than studying for the exams. This challenging final project really builds students' confidence in using other type of microcontrollers as well.

Part II of the paper lists the course topics with a brief description, while Part III elaborates on the automated car project assignment and its assessment. Part IV ponders upon the results of a survey completed by students a few weeks later when they have received the grades and considered topics for their senior capstone projects. Part V states concluding remarks with future plans.

part II: course content and objectives

Students have taken one semester-long course in each of the three fundamental areas of electrical circuits, semiconductor electronics, and C programming prior to taking a Digital Electronic course which is a prerequisite for this Embedded Systems course. With the heavy emphasis on hands-on experience at electrical \& computer engineering at this university, each of those courses has a 3-hour lab in addition to having a 3-hour lecture class. By the time students get to Embedded class, they have had rigorous lab experience and skills. This is a core course in both electrical and computer engineering programs taken in the second semester of junior year. The lab course reinforces learning and facilitates interconnecting various topics in this course. The lecture and lab courses are so tightly integrated inextricably that only a single letter grade is issued at the end.

Table 1 lists the course organization of individual topics into major sections for easier content delivery. First three sections introduce the basic architecture and instruction execution inside a real, but simple data computing processor. As the $1^{\text {st }}$ column indicates, the programming language is HCS12 assembly using Code Warrior software. At the beginning it is challenging for students to learn so much details about the hardware and how software relates to hardware actions. When they see the reasons for hardware instructions and actions and how some $\mathrm{C}$ language features (such as integer division, unsigned and signed integer operations, etc) are directly supported by processor, they realize and appreciate the reasons why certain $\mathrm{C}$ constructs were designed in particular ways. The lab component includes 5 labs, out of 10, in Assembly coding to use microcontroller ports to interface with the lights, speaker, and buttons on the Dragon12 development board.

Teaching assembly is the best way for students to understand and appreciate the detail actions carried out by the processors. It is challenging to learn and apply assembly language compared to using $\mathrm{C}$ or higher level languages since each data manipulation has to be broken down into atomic actions taken by hardware - that is the basis of Assembly code. Without learning assembly instructions, students would not realize the reason for integer division in $\mathrm{C}$ language, or why $\mathrm{C}$-code prefers $\mathrm{k}++$ in loops, and how the stack really works in function calls. They also realize the need of assembly code in order to create precise timing delays in software or very compact interface drivers. Assembly coding teaches them details about the processor and microcontroller functions and builds their confidence in applying embedded system development later on in their courses and careers. In addition, there are vast amount of resources in public domain on how to use microcontroller boards if students want to pursue a hobby or develop an entrepreneurial venture into products containing embedded systems such as drones and robots for agriculture, fishing, etc. At the end, out of over 200 individual assembly instructions with each having their own behavior of data manipulations and access mechanism, students learn and use about 30 separate instructions. Students face about ten quizzes and one formal exam related to 
assembly code. The irony is that when students get comfortable in assembly coding, the course switches to C-coding to program the microcontroller board. While assembly coding is important to learn the hardware intimately, a higher level $\mathrm{C}$ is more productive and less error prone, but equally efficient in run-time and code size which would give an advantage in power savings and required memory - particularly for micro/nano level systems.

\begin{tabular}{|l|l|}
\hline $\begin{array}{l}\text { Course Topic } \\
\text { Language }\end{array}$ & \multicolumn{1}{|c|}{ Course Topic Description } \\
\hline $\begin{array}{l}\text { Section 1 - } \\
\text { assembly }\end{array}$ & $\begin{array}{l}\text { Microprocessor and micro controller architectures: Central Processor Unit } \\
\text { architecture, its data and control registers, addressing modes, memory mapping, } \\
\text { and data flow. }\end{array}$ \\
\hline $\begin{array}{l}\text { Section 2- } \\
\text { assembly }\end{array}$ & $\begin{array}{l}\text { Assembly programming and development tools: Assembler directives and related } \\
\text { development tools, assembly language, program development for speed and exact } \\
\text { timing. }\end{array}$ \\
\hline $\begin{array}{l}\text { Section 3- } \\
\text { assembly }\end{array}$ & $\begin{array}{l}\text { Advanced Assembly Programming for embedded systems: Program loops, } \\
\text { subroutines, stack handling, memory allocation, debugging, and interfacing with } \\
\text { parallel ports. }\end{array}$ \\
\hline $\begin{array}{l}\text { Section 4- } \\
\text { C programs }\end{array}$ & $\begin{array}{l}\text { C Programming and embedded system development tools: High level C language } \\
\text { constructs for hardware access and control; tools for development, back ground } \\
\text { monitoring and debugging; Interfacing via parallel ports, and other microcontroller } \\
\text { functions }\end{array}$ \\
\hline $\begin{array}{l}\text { Section 5- } \\
\text { C programs }\end{array}$ & $\begin{array}{l}\text { Pulse Width Modulation (PWM): Motor controls, signal pulses and waveform } \\
\text { generation. }\end{array}$ \\
\hline $\begin{array}{l}\text { Section 6- } \\
\text { C programs }\end{array}$ & $\begin{array}{l}\text { Analog to Digital Conversation: Conversion techniques, different modes of } \\
\text { operation of A/D converter units, speed and accuracy trade-offs. }\end{array}$ \\
\hline $\begin{array}{l}\text { Section 7 - } \\
\text { C programs }\end{array}$ & $\begin{array}{l}\text { Interrupts and Resets: External and internally generated interrupts, interrupt } \\
\text { mechanism, reset mechanism, and priority schemes. }\end{array}$ \\
\hline $\begin{array}{l}\text { Section } 8- \\
\text { C programs }\end{array}$ & $\begin{array}{l}\text { Timers and counters: Time delay synthesis; pulse and frequency measurement, } \\
\text { event scheduling, and Waveform generation. }\end{array}$ \\
\hline
\end{tabular}

Table 1: Sections and Topics in The Embedded Systems Course

As given in Table 1, sections 4 through 8 are conducted using $\mathrm{C}$ programs including assignments and assessments. There are another 5-6 set of quizzes and one exam that fall under sections $4 \sim 8$. Five additional labs are done using $\mathrm{C}$ coding including labs for interrupt handling, 7-segment multiplexed display, and the 4x4 keyboard based "piano." Additional labs include learning about analog to digital (A2D) conversion process, how to use a sonar sensor to make distance measurements, line sensors using bidirectional write/reads, and H-bridge motor driver usage. The A2D and sonar sensor are used in the final car project, and the labs give introduction and code segments for them.

part III: automated car project assignment and assessment

The project graded as the third test and the final examination of the course carried about $30 \%$ of the weight of the class grade. It was formally assigned giving about 4 weeks before the due date. Students were advised to focus on the functionality and not the looks of the product. The toy car is a relatively inexpensive Radio Control $(\mathrm{R} / \mathrm{C})$ car available at any toy store below $\$ 25$. They typically have two 
DC motors and driven by $6 \mathrm{v}$ or $9 \mathrm{v}$ battery pack. Front wheels turn only left or right at full angle, and rear driving motors are either on or off. Four wheel trucks would be bulky and expensive, yet provides worst turn radius due to big wheels. To control the speed, rear motors are to be pulsed as on/off or pulse width modulated. Front wheels go straight if power is turned off to front motor. Also changing polarity will make it either turn left or right at full tilt. The Dragon12 board has an H-bridge to drive 2 DC motors and they work fine on a toy R/C car.

In case students decide to use stepper motors or - bridge is defective, students were provided with additional motor drivers modules. The board and motors are to be powered using small Lithium batteries made available to students, or $9 \mathrm{v}$ alkaline batteries. They were also given voltage regulators to reduce to 6 or 5 volts for DC motors. Additional components supplied were a single MaxBotix sonar sensor used for labs, a line sensor wide enough to read 2 inches using 8 LEDs so the car can track a $1 / 2$ inch wide black line on white paper, and a tiny microphone to read its analog value using A2D conversions. Students have to use many ports of the board to put everything together to build the autonomous system. They also learned the real use of switching directions on ports to make them inputs and outputs to read the black line. They were to use code segments from labs to drive ports and components. Additionally, they were also given skeleton code to manipulate the front and rear DC motors along with how to read line sensor pins. However, using bit patterns of line sensor, making 90 degree left and right turns, car stopping code, and precise on/off timing for speed control were all left for student teams to figure out to suit their particular car dynamics. How to mount the Dragon12 board on the car was also left to them.

Students were advised to treat this project as an exam. Copying and sharing code, programs, and code printouts are not allowed. Students are to form groups of 2 and each member should work equally. Each student would rate the contributions of the other member, and the ratings would impact the other member's grade for the project. These advice and detailed grading rubrics were useful to achieve good team work and have students focus on the essential tasks. Only the diagram shown in Figure 1 was supplied as an indication of the track, and no test track was provided. That make the toy car travel until the end of track is identified based on line sensors and algorithms they developed. Only dragon12 boards were allowed so that they have to develop most of the algorithms and code. Raspberry Pi or Arduino would have given prewritten code which would defeat the purpose of their learning to write basic functional code and the project based assessment.

Students came up with different algorithms to make 90-degree turns and how to get back to the black track line after going off the track for sharp turns. Track was not long enough (only 13-15 feet long) for the car to go forward and latch up to the track line again. If it somehow does not get back, student can place it manually but a portion of the points for the applicable functionality will be deducted. The emphasis was on algorithm development while building the system, and hence no provision was given to program based on a fixed track. The track used for final assessment was only seen at the morning of the actual test. No remote controllers are allowed for any function of the car. At a high level, the following, Table 2 provides the summary of actions required to be carried out, while the project was graded on many functions listed in Table 3 . Both were given to students as part of the requirements along with the formal assignment document. 


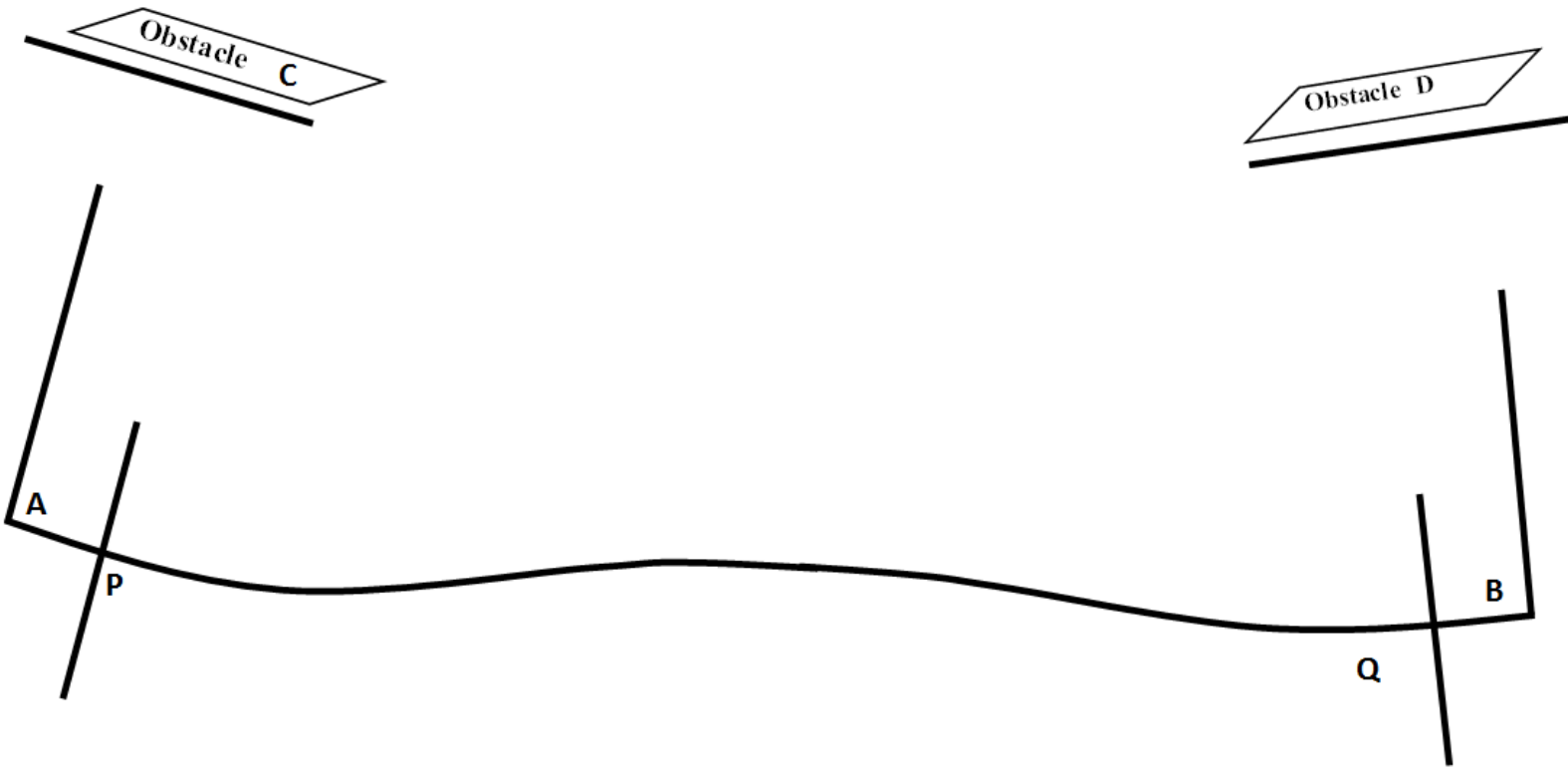

Figure 1: Diagram of the Track

1) The car is placed at A or B randomly based on a random value of 0 or 1 (selected by a computer random number generator) facing $\mathrm{P}$ or $\mathrm{Q}$ points so that its line sensor would not see the right angle.

2) Upon a loud sound, the car moves along the black line until either B left angle or A right angle is seen depending on the starting end.

3) It should ignore black crossing lines at $\mathrm{P}$ and $\mathrm{Q}$ completely.

4) After the car clears both crossing lines, it should be checking for obstacles using the sonar sensor while still following the black line (which is now relatively straight) until it sees either A or B bend (90 degrees). If an obstacle is seen within 12 to 15 inch distance, the car stops and waits for the object to move away. Then it continues.

5) Then car needs to take the turn at either A or B toward the obstacles (either C or D, respectively) and goes closer to it so it is within 1 to 2 feet, but not too close to hit C or D. Lines $\mathrm{E}$ and $\mathrm{F}$ are a few inches away from obstacle $\mathrm{C}$ or $\mathrm{D}$. The car does not care about $\mathrm{E}$ or $\mathrm{F}$ line, just the distance to $\mathrm{C}$ or $\mathrm{D})$.

6) Then the car stops. When stopped, it should show the distance to the Obstacle on LCD display.

7) (Optional) After a few seconds pause, the car may drive away parallel (have to make another 90 degree turn) to $\mathrm{E}$ or $\mathrm{F}$ for a few feet.

Table 2: Summery of Actions Required or Desired 


\begin{tabular}{|l|l|}
\hline \multicolumn{1}{|c|}{ Function } & \multicolumn{1}{c|}{ Grading scale } \\
\hline Start on Sound & Yes/No \\
\hline Able to travel straight & 12345 \\
\hline Follow left \& right curves & 12345 \\
\hline Make 90-degree right turn & 12345 \\
\hline Make 90-degree left turn & 12345 \\
\hline Total distance travelled on line & Portion $1 / 4,1 / 2,3 / 4,100 \%$ \\
\hline Time taken to complete & Min, seconds \\
\hline Stopped 1 to 2 feet from finish line & 12345 \\
\hline Travel parallel at finish line & 12345 \\
\hline Pause for dynamic obstacle & 12345 \\
\hline Stop without hitting any object & Yes/No \\
\hline
\end{tabular}

Table 3: Project Assessment Rubric

part IV: students' feedback on the project

Students performed well in their attempts and final finished car. The fastest car took 90 seconds. Majority of the cars followed the required path and performed well. Some of the cars went off track and had to be interviewed to place back on track at turns, resulting in slowest times to complete. Their programming code was provided for examination to make sure no collaboration in terms of sharing code was done. They were allowed to help and explain how to connect and built the hardware platform, but not actual coded algorithms - this being an exam. Figure 2 below shows a picture of the fastest car on the final track. The thin strip in the front was the line sensor providing 8 bit values of 0 or 1 depending on black or white surface.

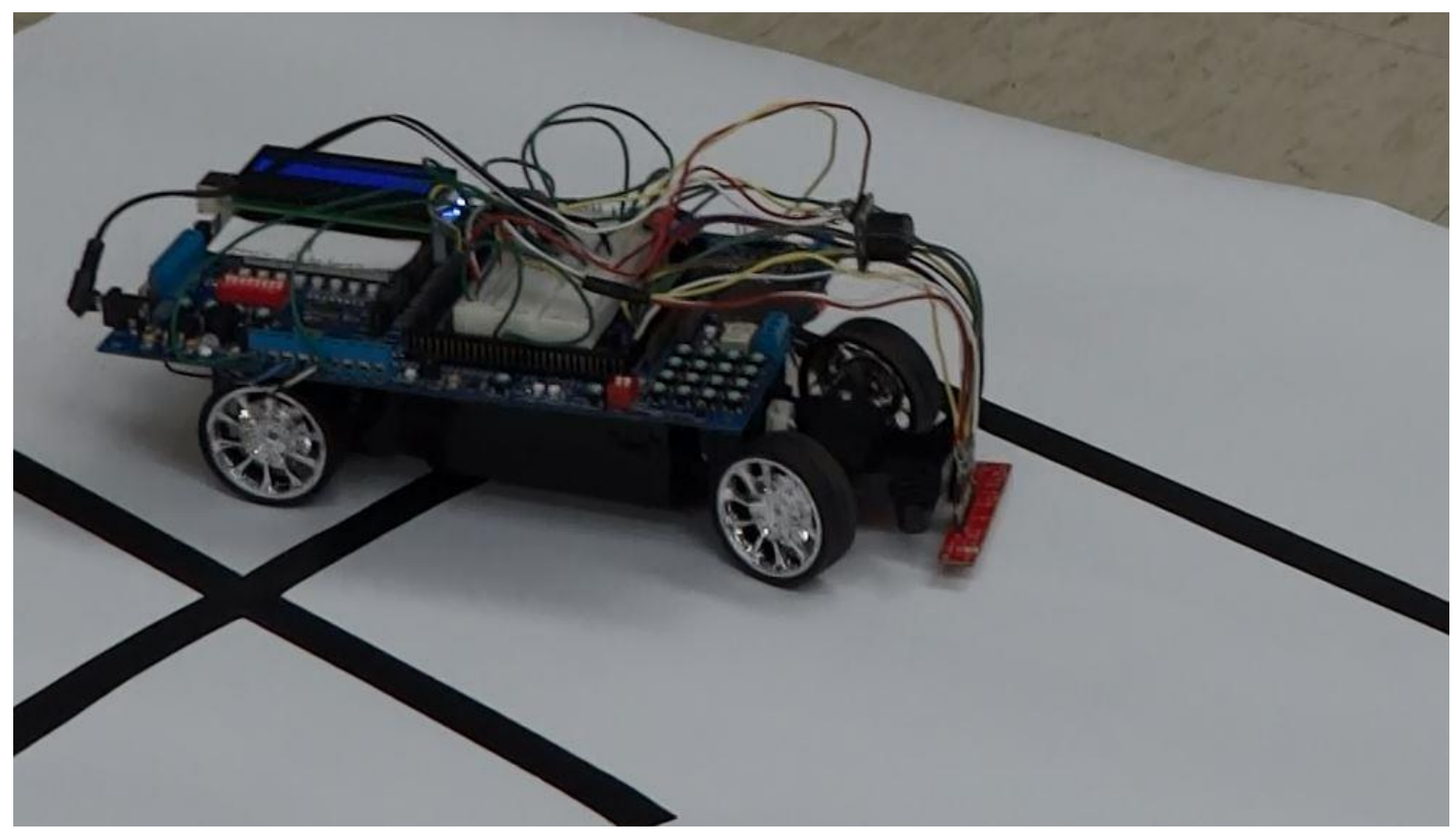

Figure 2: A Student Car on the Actual Track. 
This being a more challenging course than an average course taken by electrical and computer students, they worked diligently to complete the project. As observed, they learned a lot from getting their self-built system to work - sometimes trying different ways, which really taught them engineering practices. Persistence is the key to achieving success. After the final event, some students expressed that they really understood how a microcontroller works and learned lot more from this project than from studying notes and the text.

Students were surveyed after they received the final class grades allowing them time to develop their own perspective on the project and many long hours they spent on it. The objective of the survey was to gauge the effectiveness of having the project as an exam and decide whether they think a written exam would have been better. The survey was collected from 16 students who were the Embedded Systems student body. Since they had already taken two written exams and many quizzes they must have had some understanding of what a final exam would be like. This course has only one section and it was not possible to have a parallel control group to gather data for comparison. Even if there were another section, it would be impossible not to offer the project option to that class also. The author feels that almost all would have taken the project option making the control group very small.

The survey results are summarized qualitatively in Table 3. The responses were given based on the typical rubrics of 1 to 5 (1-strongly disagree, 2-disagree, 3-neutral, 4-agree, 5-strongly agree). Column 2 lists what each question was trying to assess from students' perception and knowledge. The $3^{\text {rd }}$ column shows the average rubric score given by students for each question. Final column in Table 3 attempts to give a qualitative meaning to the data in column 3 so that author can make qualitative adjustments to this project in the future.

\begin{tabular}{|c|l|l|l|}
\hline & \multicolumn{1}{|c|}{ Essence of the question asked } & Average & Qualitative \\
\hline 1. & $\begin{array}{l}\text { In EET 1132 Embedded Systems course I learned how to } \\
\text { programs a microcontroller. }\end{array}$ & 4.4 & Yes \\
\hline 2. & I think I did ok in that course + lab. & 4.4 & Yes \\
\hline 3. & $\begin{array}{l}\text { In that course I had to learn lots of details about } \\
\text { microcontroller and its inside. }\end{array}$ & 4.2 & Yes \\
\hline 4. & $\begin{array}{l}\text { I learned a more by doing the car project than by studying for } \\
\text { a written exam }\end{array}$ & 4.7 & Yes \\
\hline 5. & $\begin{array}{l}\text { I worked well with the project partner to achieve a good grade } \\
\text { for car project. }\end{array}$ & 4.7 & Yes \\
\hline 6. & $\begin{array}{l}\text { My project partner worked well with me on the project to } \\
\text { achieve a good grade for car project. }\end{array}$ & 4.8 & Yes \\
\hline 7. & $\begin{array}{l}\text { I would have been better off not having a partner (work alone) for } \\
\text { car project. }\end{array}$ & 1.6 & No \\
\hline 8. & $\begin{array}{l}\text { The car project was too challenging for me and for my project } \\
\text { partner. }\end{array}$ & 1.6 & No \\
\hline 9. & $\begin{array}{l}\text { I think the track and the requirements were too challenging for } 2 \\
\text { people. }\end{array}$ & 1.9 & Not really \\
\hline 10. & $\begin{array}{l}\text { I would have been more exciting, if we had few other cars on the } \\
\text { track at the same time. }\end{array}$ & 2.1 \\
\hline
\end{tabular}

Table 3: Student Survey Results 
Almost all the questions posed to students received an affirmative answer of solid "yes" in the qualitative score for questions 1 through 6 indicating that the students liked the project as the exam, and its format was good. Questions 7 through 9 indicate the partnering pairs worked, and the last question indicates that they would prefer keeping the requirements simple as was. Having more cars on track would pose additional challenges of having to process more sensors and far more complex algorithms.

part V: conclusion

The decision to introduce a microcontroller development board based project in lieu of a final exam was done with ample caution and care so as not to overwhelm students having to spend too much time very close to the final exam periods of other classes. Although, (having done the labs) they are familiar with the hardware development board and software platform, a self-driving car project involving several sensors would be challenging when it has to really work without debugging help from the instructor. Additionally, they had not used the H-bridge to drive any motors before. Author plans to add a lab or a section to a lab on H-bridge usage to make them familiar with components.

In conclusion, the incorporation of a hardware/software project to challenge students' engineering abilities and topics they learned on microcontrollers was successful. It would certainly benefit them by increasing their self-confidence on facing new engineering problems in future. That is a very valuable learning - more learning than a particular set of text book topics would provide. The author as the instructor has to put in a considerable effort to formulate and support this project which is much more than grading a written exam. However, with the level of benefit it brings to students, the author plans to continue similar projects in future offerings of the course.

references:

[1] User Manual, Dragon-12 plus Microcontroller Programming Board http://www.evbplus.com

[2] "The Right Tool for the Job," http://hammerprinciple.com/therighttool/items/matlab/c 2012

[3] Raspberry Pi microcontroller projects at http://www.instructables.com/id/Raspberry-Pi-Projects/

[4] Frontoni, E., Mancini, A., Caponetti, F., Zingaretti, P., "A framework for simulations and tests of mobile robotics tasks", Control and Automation, 2006. MED '06, The 14th Mediterranean Conference on Control and Automation.

[5] Nelson, M.L., Rice, D., "Introduction To Algorithms And Problem Solving", Proceedings 2000 Frontiers in Education Conference, Oct. 2001, Kansas City, MO.

[6] Raymond, D.R., Welch, D.J., "Integrating Information Technology And Programming In A Freshmen Computer Science Course", Proceedings 2000 Frontiers in Education Conference, Oct. 2001, Kansas City, MO. 
[7] Ludi, S. Collofello, J., "An analysis Of The Gap Between The Knowledge And Skills Learned In Academic Software Engineering Course Projects And Those Required In Real Projects", Proceedings 2001 Frontiers in Education Conference, Oct. 2001, Reno, NV.

[8] HCS12 / 9S12 : Introduction to Software \& Hardware Interfacing , H. Huang Thompson - Delmar Learning, 2009

[9] Fincher, S., "What are We Doing When We Teach Programming?," Proceedings 1999 Frontiers in Education Conference, No. 1999, San Juan, PR,

[10] “Programming in C," $3^{\text {rd }}$ edition by Stephen G. Kochan, ISBN-10: 0-672-32666-3, Sams Publishing 2004

[11] Feedback Systems, An Introduction for Scientists and Engineers, K Astrom and R. Murray, 2010 Princeton University Press

[12]. "Freescale CodeWarrior IDE," at www.nxp.com 